\title{
Therapeutic drug monitoring: a key point in optimal treatment of invasive fungal disease
}

\author{
Jan Styczyński iD \\ Department of Pediatric Hematology and Oncology, Collegium Medicum in Bydgoszcz, Nicolaus Copernicus University in Toruń, \\ Jurasz University Hospital 1, Bydgoszcz, Poland
}

Invasive fungal disease (IFD) remains a complication with high mortality, particularly in patients with acute leukemia, and in the setting of hematopoietic cell transplantation. In the strategy of management of IFD, azoles are one of the mainstay drugs. In order to maintain the correct therapeutic range of azoles which is both efficient and safe for the patient, therapeutic drug monitoring (TDM) is recommended [1]. In alignment with this, Polish scientific societies have recently recommended the use of posaconazole and voriconazole in various clinical conditions and strategies, with the support of TDM [2-5].

In this issue of "Acta Haematologica Polonica", Liszka et al. [6] in a pilot study present, for the first time in Poland, the use of TDM in IFD. The authors show that therapeutic drug monitoring of posaconazole is an effective approach to therapy of invasive fungal infections in pediatric patients. To determine drug concentration, they used the high-performance liquid chromatography with fluorescence detector (HPLC-FLD) method, which is currently regarded as the optimal standard for TDM for azoles [1, 7].

We must always bear in mind that the likelihood of toxicity associated with supratherapeutic azole serum concentrations can be as high as quadruple that of therapeutic concentrations [7], and that adequate TDM can prevent many adverse events. Our previous experience with IFD and its management $[8,9]$ indicate the need for more efficacious antifungal treatment.

Nevertheless, the current Polish guidelines $[2,5]$ are in line with increasing safety and efficacy in the treatment of infectious complications, something particularly necessary due to the development of new targeted anticancer therapy [10]. Therapeutic drug monitoring for antifungal azoles is still an unmet medical need, although we have taken a significant step forward.

\section{Authors' contributions}

JS - sole author.

\section{Conflict of interest}

Nothing to disclose.

\section{Financial support}

No financial support.

\section{Ethics}

The work described in this article has been carried out in accordance with The Code of Ethics of the World Medical Association (Declaration of Helsinki) for experiments involving humans; EU Directive 2010/63/EU for animal experiments; Uniform requirements for manuscripts submitted to biomedical journals.

\section{References}

1. Lehrnbecher T, Averbuch D, Castagnola E, et al. 8th European Conference on Infections in Leukaemia, 8th European Conference on Infections in Leukaemia. 8th European Conference on Infections in Leukaemia: 2020 guidelines for the diagnosis, prevention, and treatment of invasive fungal diseases in paediatric patients with cancer or post-haematopoietic cell transplantation. Lancet Oncol. 2021; 22(6): e254-e269, doi: 10.1016/S1470-2045(20)30723-3, indexed in Pubmed: 33811813.

2. Gil L, Kałwak K, Piekarska A, et al. Antifungal management in adults and children with hematological malignancies or undergoing hematopoietic cell transplantation: recommendations of Polish Society of Hematology and Blood Transfusion, Polish Society of Pediatric Oncology and Hematology, and Polish Adult Leukemia Study Group, 2020. Acta Haematol Pol. 2020; 51(2): 60-72, doi: 10.2478/ahp-2020-0014.

3. Styczyński J, Czyżewski K, Ussowicz M, et al. Antimicrobial prophylaxis in patients after hematopoietic cell transplantation: results of a survey
Address for correspondence: Jan Styczyński, Department of Pediatric Hematology and Oncology, Collegium Medicum, Nicolaus Copernicus University Toruń, Skłodowskiej-Curie 9, 85-094 Bydgoszcz, Poland, phone +48525854860, fax +485258540 87, e-mail: jstyczynski@cm.umk.pl Received: 22.10.2021

Accepted: 22.10 .2021

\section{PTHiT Copyright $\odot 2021$}

The Polish Society of Haematologists and Transfusiologists, Insitute of Haematology and Transfusion Medicine. All rights reserved. 
of the Polish Federation of Bone Marrow Transplant Centers. Acta Haematol Pol. 2020; 51(3): 183-186, doi: 10.2478/ahp-2020-0032.

4. Styczyński J, Czyżewski K, Ussowicz M, et al. Antimicrobial prophylaxis in patients after hematopoietic cell transplantation: results of a survey of the Polish Federation of Bone Marrow Transplant Centers. Acta Haematol Pol. 2020; 51(3): 183-186, doi: 10.2478/ahp-2020-0032.

5. Styczyński J, Piekarska A, Zaucha-Prażmo A, et al. Antimicrobial prophylaxis in adults and children undergoing hematopoietic cell transplantation: 2021 Polish recommendations. Acta Haematol Pol. 2021; 52(6): 528-542, doi: 10.5603/AHP.a2021.0097.

6. Liszka K, Resztak M, Zalewska P, et al. Therapeutic drug monitoring of posaconazole for effective prophylaxis of invasive fungal infections in pediatric patients. A pilot study. Acta Haematol Pol. 2021; 52(6): 578-583, doi: 10.5603/AHP.2021.0096.
7. Luong ML, Al-Dabbagh M, Groll AH, et al. Utility of voriconazole therapeutic drug monitoring: a meta-analysis. J Antimicrob Chemother. 2016; 71(7): 1786-1799, doi: 10.1093/jac/dkw099, indexed in Pubmed: 27165788.

8. Styczyński J. Infectious complications in children and adults with hematological malignancies. Acta Haematol Pol. 2019; 50(3): 167-173, doi: 10.2478/ahp-2019-0027.

9. Styczyński J, Czyżewski K, Frączkiewicz J, et al. Clinical spectrum and outcome of invasive mucormycosis in children and adults: Polish experience of the decade 2010-2019. Acta Haematol Pol. 2020; 51(3): 157-163, doi: 10.2478/ahp-2020-0028.

10. Giebel S, Basak G, Bieniaszewska M, et al. Current status and progress of Polish hemato-oncology. Acta Haematol Pol. 2021; 52(1): 4-17, doi: 10.5603/AHP.2021.0003. 